DOI: $10.13037 /$ ci.vol21n45.6116

\title{
Discursos sobre masculinidades e futebol moderno: identidade e diferença no "decreło Cenas Lamentáveis"
}

DISCOURSES ABOUT MASCULINITIES AND MODERN FOOTBALL: IDENTITY AND DIFFERENCE IN THE "CENAS LAMENTÁVEIS DECREE"

\author{
- Elyson Gums ${ }^{1}$ \\ ORCID: https://orcid.org/0000-0002-7315-0099 \\ (Universidade Federal do Paraná, Programa de Pós-Graduação em Comunicação. Curitiba - PR, \\ Brasil)
}

\section{Fábio Hansen ${ }^{2}$}

ORCID: https://orcid.org/0000-0003-2997-4602

(Universidade Federal do Paraná, Programa de Pós-Graduação em Comunicação. Curitiba - PR, Brasil)

\section{Resumo}

Neste artigo são analisados os decretos postados pela fanpage Cenas Lamentáveis, pelo tencionamento com teorias sobre identidade e sobre masculinidades. $\mathrm{O}$ objetivo é compreender o funcionamento discursivo do decreto e suas relações com gênero e com a noção de "futebol clássico". São mobilizadas ainda as noções teóricas de efeito-leitor e de silêncio, oriundas da Análise de Discurso pecheutiana. Análises revelam o decreto como parte de um sistema de demarcação de diferença, e responsável por institucionalizar a visão de que "futebol clássico" é futebol praticado por detentores das masculinidades socialmente legitimadas.

Palavras-Chave: Identidade e diferença. Masculinidades. Futebol moderno.

\section{Abstract}

This article proposes to analyse decrees posted by fanpage Cenas Lamentáveis, per tensioning with theories of identity and masculinities. The objective is to understand the discursive functioning of the decrees and its relations with gender and the notion of "traditional football". Theoretical notions of readereffect and silence are mobilized, from the pecheutiana Discourse Analysis. Analyzes reveal the decrees as part of a system of demarcation of difference, and responsible for institutionalizing the view that "classic football" is played by holders of socially legitimated masculinities.

Keywords: Identity and difference. Masculinities. Modern football. 


\section{Introdução}

Este artigo faz parte da dissertação de mestrado do autor, ainda em desenvolvimento, na qual são analisados aspectos de construções de masculinidades em um contexto de contraidentificação a um futebol mercantilizado. A premissa deste trabalho é a de que gênero é uma categoria importante para definir o que é esse futebol (LOPES, 2015; SANTOS, 2016b). Há escassa produção científica sobre o assunto na área de Comunicação, o que ajuda a solidificar a justificativa da dissertação e deste recorte'.

O objeto empírico é a fanpage Cenas Lamentáveis ${ }^{2}$, selecionada por sua relevância no nicho de "futebol tradicional", mas sobretudo por ter desenvolvido formas particulares de comunicação com seus seguidores, como os decretos. A CL se define como entusiasta do "[...] futebol clássico brasileiro, os anos 90, período em que tivemos craques de personalidade forte, que não tinham medo de dar uma entrevista provocativa [...]" (CENAS LAMENTÁVEIS, 2016).

Os decretos são espécies de materializações da "linha editorial" seguida pela página. São posts que chancelam uma série de práticas moralmente condenáveis ${ }^{3}$, em que se percebem atributos de masculinidades hegemônicas/cúmplices (CONNELL, 2005). A problemática deste artigo reside na sobreposição das ideias do decreto como pedagogia do que é ser homem e do que é ser parte da comunidade Cenas Lamentáveis, e de quais maneiras isso se relaciona a uma formação discursiva do "futebol clássico brasileiro" existente no decreto.

Considera-se o decreto como potencialmente indicativo da identidade do grupo, dado o alto engajamento desse tipo de post. Por isso ele foi selecionado como corpus. Os sentidos ali presentes são tencionados também com estudos sobre masculinidades em contextos esportivos (BANDEIRA, 2009; MESSNER, 2007) e com conceitos de identidade e diferença (WOODWARD, 2014; SILVA, 2014), para averiguar como/se eles atuam sobre a identidade dos seguidores.

A suposta participação do decreto na formação de identidade se dá pela forma como os sujeitos consomem os sentidos postos em circulação ali. Consumo é entendido como construção cultural, pela qual podem-se criar sentidos de "[...] pertencimento,

\footnotetext{
1 "Gênero" é presente em alguns trabalhos que envolvem modernização do futebol, mas sem muita profundidade. Mais dados sobre as interfaces gênero e futebol no Brasil foram levantados em pesquisa da pesquisa produzida pelo autor.

2 A página foi criada em 2014 e tem 662 mil curtidas. Acesso em: 25/11/2018. Desse ponto em diante, também referida por Cenas ou CL Disponível em:.https://www.facebook.com/CenasLamentaveis/.

3 Exemplo de decreto disponível em https://pt-br.facebook.com/CenasLamentaveis/posts/aten\%C3\%A7\%C3\%A3odecreto-de-carnaval-leia-na-voz-de-m\%C3\%A1rcio-canuto-o-caps-lock-humanoboa-ta/1858636747740522/. Acesso em 25 nov. 2018.
} 
exclusão, subjetivação, dentre tantos outros [...]” (AIRES, HOFF, 2012, p. 13). Nesta perspectiva consumo é necessariamente comunicacional e ocorre por meio da linguagem. Assim, se estabelece uma relação entre comunicação, discurso e consumo, por meio da interpretação dos sujeitos e pelo efeito de produção de sentido.

Sendo assim, a Análise de Discurso de linha francesa ${ }^{4}$ (ORLANDI, 2005; 2007) é adotada como referencial teórico-metodológico, por permitir observar as condições de produção desses decretos e os sentidos que estão além do explícito nos textos. São adequadas ao objeto especialmente as noções de efeito-leitor, de Pêcheux, pois possivelmente imagens projetadas pelos administradores influenciam nos sentidos produzidos; e as proposições de Orlandi sobre a "política do silêncio", visto que os "ditos" do decreto potencialmente apagam dali uma série de outros sentidos e tentam mesmo suprimir a existência de outros sujeitos.

\section{Futebol moderno, futebol clássico, e Cenas Lamentáveis}

$C L$ existe em Facebook, Twitter, Instagram e tem loja e site próprios, com foco em conteúdo humorístico. A seção "quem somos" do site oficial descreve uma página que exalta o futebol clássico brasileiro, os anos 90, a personalidade forte dos jogadores, a festa das torcidas e a cerveja. Por mais que as palavras não estejam no texto, Cenas se entende “contra o futebol moderno". A expressão diz respeito a um movimento de torcedores contrários à elitização/midiatização do futebol. (SANTOS, 2016a; LOPES, 2015).

Exemplos de transformações que originaram esse "novo futebol" são mudanças estruturais nos estádios ingleses na década de 1980; os valores exorbitantes do mercado do futebol mundial; e no caso brasileiro, a construção das arenas multiuso para a Copa do Mundo de 2014. (SANTOS, 2017, 2016a, 2016b, 2014; LOPES, 2015; WILLIAMS, 2016; KENNEDY, KENNEDY, 2014). Com exceção de Williams (2006), os autores citados são críticos a esse momento e veem esse futebol como "pasteurizado" e excludente.

Portanto, ser "contra o futebol moderno" significa de algum modo se identificar com outro modelo. A categoria gênero é presente em algumas análises da contraidentificação com o elitizado, mas sem aprofundamentos. Santos (2016b; 2017) critica uma espécie de "nostalgia reacionária" que veria o futebol pré-moderno como "futebol de macho" apenas; Lopes (2015) conjectura que algumas práticas reprimem grupos minoritários; e Williams (2006) cita a construção da masculinidade de jogadores da Seleção Inglesa como aspecto inclusivo do esporte, contrário ao estereótipo do hooligan.

4 Por "linha francesa", entende-se estudos pecheutianos. Daqui em diante a escrita será AD. 
Uma das formas pelas quais a CL comunica seus valores aos seguidores especialmente a "personalidade forte", "a festa" e "muita cerveja", são os decretos.

\section{Breve descrição do decreto Cenas Lamentáveis}

Um primeiro movimento analítico foi a construção de um corpus que permitisse responder ao problema de pesquisa (ORLANDI, 2005; MOLETA, 2018), que envolve os modos pelos quais os discursos sobre masculinidades presentes no decreto de Cenas Lamentáveis se articulam com a valorização de um estilo "clássico" de futebol.

Todos os posts até outubro de 2018 foram coletados com o Netvizz5; em seguida foram selecionados arbitrariamente cinco decretos de cada ano, que serviram como base para compreender a essência e traçar um rápido histórico do objeto.

Decretos são postados por volta de $17 \mathrm{~h}-18 \mathrm{~h}$ das sextas-feiras e declaram aberto o final de semana de administradores e seguidores. São institucionalizados e mesmo uma "demanda popular", o que se traduz nas interações com esses posts, que muito frequentemente passam de 1000 comentários. Transparece, nesse engajamento com o conteúdo, o sentido de pertencimento proporcionado pelo consumo (GARCÍACANCLINI, 2015; BACCEGA, 2012), já que de algum modo, há uma organização social em torno do decreto, visto que ele é solicitado pelos seguidores.

Consumo, assim, é território de interações entre sujeitos, onde as identidades são construídas e negociadas pela produção de sentido dos sujeitos, participantes ativos do processo comunicacional. Por meio do consumo de sentidos existentes e da produção de seus próprios sentidos, se revela “[...] a identidade do sujeito, seu 'lugar' na hierarquia social, o poder de que se reveste. Como os meios de comunicação, o consumo também impregna a trama cultural" (BACCEGA, 2012, p. 260).

O primeiro resultado da busca aponta para $2015^{7}$ e desde então o decreto se repete de forma quase ritualística, com linguagem e formatos bem definidos. Varia em tamanho, mas em geral é um parágrafo escrito sem pontuação, com algumas palavras destacadas

\footnotetext{
${ }^{5}$ Aplicação do Facebook que permite a coleta de dados públicos do site para fins acadêmicos. Disponível em: https:// apps.facebook.com/107036545989762/?ref=br_rs. Acesso em: 03 out. 2018.

6 Decreto de 27/07/2018: "Vocês pediram PRA C $* * * * * *$, vocês votaram, o resultado foi MASSACRANTE. Portanto está de volta o maior Decreto [...]”. Disponível em: https:/www.facebook.com/1427018470902354/ posts/2140665519537642/. Acesso em: 17 dez. 2018.

7 Em 2016, o decreto teve repercussão nacional por meio do jornalista Alê Oliveira, que criou decretos próprios no programa Bate-Bola da ESPN, inspirado na Cenas Lamentáveis. Disponível em: https://uolesportevetv.blogosfera. uol.com.br/2016/10/07/decreto-vira-moda-na-espn-e-ale-oliveira-brinca-tenho-de-ter-bom-senso/. Acesso em: 17 dez. 2018.
} 
em caixa alta e uso frequente de linguajar chulo. Mais do que a forma, os sentidos produzidos também são majoritariamente os mesmos - uma paráfrase (ORLANDI, 2005) momento em que é dita a mesma coisa de formas diferentes ${ }^{8}$, em uma espécie de "retorno ao mesmo".

É incentivada, em forma de sátira, uma série de comportamentos destrutivos e/ ou contraventores, em especial consumo de álcool em excesso, brigas e atividade sexual hétero. Nos decretos, essas condutas são relacionadas a jogadores de futebol "irreverentes", como Adriano Imperador, Aloísio Chulapa e Ronaldinho Gaúcho. Uma ótica possível de observar o decreto é por meio das noções de identidade e diferença (WOODWARD, 2014; SILVA, 2014), conforme desenvolvido na próxima seção.

\section{O decreto como produtor de identidade e diferença}

Identidade não existe em essência, ela é fruto de um complexo processo discursivo e de práticas sociais dos sujeitos, o que lhe confere caráter instável, móvel e não acabado (WOODWARD, 2014; SILVA, 2014). Segundo tal abordagem, a identidade depende de marcações simbólicas que a difere das outras. Por exemplo, ao dizer que "sou" algo, ao mesmo tempo se diz que "não sou" uma série de outras coisas. Para Orlandi (2005, 2007) esse é um funcionamento básico da linguagem e dos mecanismos pelo qual opera o silêncio.

Woodward (2014, p. 41) afirma que "as formas pelas quais a cultura estabelece fronteiras e distingue a diferença são cruciais para compreender as identidades. A diferença é aquilo que separa uma identidade da outra, estabelecendo distinções, frequentemente na forma de oposições". Elas podem ocorrer por meio de sistemas simbólicos de representação ou por sistemas classificatórios.

Tal diferenciação pressupõe relações de poder imbricadas à significação e à classificação. Retomando o pensamento de Derrida, Silva e Woodward enfatizam que não é possível compreender essa classificação como um sistema dicotômico simplificado, sob o risco de validar relações assimétricas de poder, mas sim com possibilidade de diferentes tomadas de posição entre esses dois espectros. A representação também faz parte do quadro teórico como forma pelas quais os sujeitos são posicionados em relação

\footnotetext{
${ }^{8}$ Exceção foi um decreto especial postado em 2017, em homenagem à queda do avião da Chapecoense. O post tinha um ar muito mais sério e estimulava apoio ao time. Disponível em: https://www.facebook.com/CenasLamentaveis/photos/a.1427579367512931.1073741828.1427018470902354/1814149555522575/?type=3\&_mre$\mathrm{f}=$ message_bubble. Acesso em: 17 dez. 2018.
} 
aos papéis sociais que ocupam (WOODWARD, 2014, apud HALL, 1997); e como aquilo que possibilita a definição da identidade (SILVA, 2014).

É por meio da repetição - a "memória" ou o interdiscurso (ORLANDI, 2005, 2007) - que se atribui institucionalidade a um sentido. No caso do decreto, a repetição de sentidos legitimaria comportamentos violentos/autodestrutivos; potência sexual; farra etc. como o "estilo $C L$ ", por mais que esses comportamentos não aconteçam na vida real.

A partir daí, pode-se ver com clareza marcas das relações de poder (SILVA, 2014) no decreto. O pertencimento é definido pela legitimidade dos comportamentos destacados; quem pode estar no grupo são os praticantes/cúmplices; comportamentos contrários sequer são dignos de aparecerem no decreto, logo podem ser interpretados como inferiores; e sua reprodução há anos normatiza esta como a identidade do grupo.

A partilha desses atributos evidencia também a sensação de pertencimento proporcionada pelo consumo. Os atributos simbólicos do decreto, istoé, os comportamentos celebrados por ele, circulam entre os sujeitos e são consumidos por eles por intermédio da linguagem, configurando os posts como constituintes da identidade do grupo como um todo (BACCEGA, 2012) e o consumo como ordenador social desse grupo (GARCÍACANCLINI, 2015). O próximo passo é relacionar a "identidade CL" com futebol.

\section{Modelos de masculinidade no futebol}

O decreto está relacionado a atributos de masculinidade hegemônica (CONNELL, 2005; CONNELL, MESSERSCHMIDT, 2013) futebolística. O conceito faz parte dos estudos sobre hierarquias de masculinidades de Connell (2005). Os diferentes tipos de masculinidade que coexistem em sociedade não são entendidos como categorias estanques e estão passíveis de mudança e contestação, tal como a identidade.

A masculinidade hegemônica é, sobretudo, um "mecanismo de defesa" do patriarcado. Trata-se do conjunto de práticas legitimadas em determinado contexto social,

que define "o que é ser homem" e necessariamente legitima a dominação do masculino sobre o feminino. Essa hegemonia se dá pela "bem-sucedida afirmação de autoridade, mais do que [pela] violência direta" (CONNELL, 2005, p. 77), por mais que às vezes a violência dê sustentação à hegemonia.

Há também as masculinidades subordinadas, aquelas que sofrem os efeitos da dominação da masculinidade hegemônica. É o caso dos homens gays, por exemplo. Cúmplices são aqueles que não reproduzem as práticas hegemônicas, mas gozam dos 
privilégios do patriarcado; e as marginalizadas são aquelas produzidas dentro de grupos "desautorizados", como as minorias étnicas.

Na investigação de Bandeira (2009) sobre masculinidades em jogos de Internacional e Grêmio, os principais atributos destacados por ele são a virilidade, o consumo de álcool e a garra. Há afeto para quem é "como nós" e agressão para quem é diferente - os rivais são também classificados como "menos homens". O autor se referia a um contexto específico, mas outras pesquisas empíricas apontam resultados semelhantes. Soares et al. (2016) sugerem que a predileção por esses valores interdita outros, como "a 'indolência', a 'fraqueza' e a 'falta de vigor'.

Messner (2007) argumenta que essas masculinidades "violentas" são defesas às mudanças nos ambientes de trabalho e familiares, primeiro no período da Revolução Industrial; depois nos períodos pós-Guerra e de viradas no capitalismo. Os esportes modernos, aponta o autor, são uma forma de o homem afastar-se de um "mundo feminizado" e manter um elo com um "passado patriarcal", por assim dizer.

No decreto, está posto o que Soares et al (2017, p. 1156) chamam de "'tipo viril ideal' idealizado nos discursos [e que] ocuparia centralidade em um projeto esportivo que se pretenda "vitorioso", por meio da violência/autodestruição, independência e objetificação da mulher etc. - ou seja, ignora o que é associado às masculinidades subordinadas. Na próxima seção, são explicados os procedimentos metodológicos que permitem a compreensão do discurso presente em Cenas.

\section{Procedimentos metodológicos da AD}

O conjunto de textos que serviu para a descrição do decreto foi delimitado devido ao entendimento de que não seria necessário analisar todos, uma vez que os sentidos se repetem. Foram selecionados os dois de cada ano com maior número de comentários oito textos, portanto - e em seguida um que fosse representativo dos demais e adequado a responder a problemática de pesquisa. A abordagem de analisar apenas um decreto está relacionada à "exaustividade vertical" pretendida pela $\mathrm{AD}$, que não tem como objetivo análises quantitativas, mas sim qualitativas em profundidade (ORLANDI, 2005). 
O post analisado é um decreto especial de carnaval ${ }^{9}$, do qual foram extraídas uma série de Sequências Discursivas (SDs) ${ }^{10}$. A análise se deu com base em dispositivos teórico e analíticos (ORLANDI, 2005), compostos pelo recorte e mobilização de noções teóricas específicas da teoria do discurso.

Durante todas as etapas da pesquisa, ocorre interpretação - o analista descreve a interpretação de sujeitos, e ao mesmo tempo que o faz, ele próprio interpreta (ORLANDI, 2005). Esses dispositivos servem para dar embasamento às interpretações do analista, evitando subjetivações e achismos. Não se espera neutralidade do pesquisador, até porque ele não está "fora" do funcionamento do discurso, apenas o compreende (e nesse momento o produz) a partir de outra posição (BENETTI, 2016).

As noções-chave dessa pesquisa são as de efeito-leitor, formuladas por Pêcheux (MOLETA, 2018; HANSEN, 2013); e de silêncio, desenvolvida por Orlandi (2007). São mobilizados ainda os conceitos de interdiscurso (ORLANDI, 2005, 2007) e de Formação Discursiva (ORLANDI, 2005; BENETTI, 2016), complementares à compreensão do funcionamento discursivo.

O interdiscurso é "[...] todo o conjunto de formulações feitas e já esquecidas que determinam o que dizemos. Para que minhas palavras tenham sentido é preciso que elas já façam sentido" (ORLANDI, 2005, p. 36). Isso ocorre por meio de um jogo de esquecimentos ${ }^{11}$ que constitui o dizer.

É essa dialogia entre os discursos, e a premissa de a AD trabalhar a linguagem em sua exterioridade - contextos históricos e culturais, a prática dos sujeitos (BENETTI, 2016; ORLANDI, 2005, 2007) - que tornou necessário contextualizar a contraidentificação ao futebol moderno e a historicidade de determinada construção de masculinidade no futebol. A paráfrase também se relaciona à interdiscursividade.

A Formação Discursiva (FD) permite ao analista estabelecer regularidades entre um sentido disperso por vários textos. Ela "determina o que pode e deve ser dito" (ORLANDI, 2005 , p. 43), de modo que um sujeito está sempre inscrito em uma FD. O discurso é produzido "[...] da relação regulada historicamente entre as muitas formações discursivas (com seus muitos sentidos possíveis que se limitam reciprocamente)" (ORLANDI, 2007, p. 21).

\footnotetext{
9 Disponível em: https://www.facebook.com/1427018470902354/posts/1858636747740522/. Publicado em 24/02/2017. Acesso em: 09/12/2018. Embora possa se assumir um contexto "permissivo" durante o carnaval, os mesmos comportamentos deste decreto estavam presentes nos demais.

10 São trechos significativos de texto - no caso, frases do decreto - escolhidos arbitrariamente pelo pesquisador por conterem elementos que permitam responder à questão de pesquisa (BENETTI, 2016).

11 1. O esquecimento da enunciação (todas as coisas poderiam ser ditas de outras formas) e 2. O esquecimento da ideologia (a ilusão de que somos donos do que dizemos, o esquecimento de toda a cadeia de sentidos anterior a nós). (ORLANDI, 2005 apud PÊCHEUX, 1975)
} 
$\mathrm{Na} \mathrm{CL}$, foi identificada a Formação Discursiva "futebol clássico", que engloba uma série de saberes definidores do que é esse futebol, e a partir da qual os sujeitos produzem sentidos sobre o esporte e sobre masculinidade. As seções seguintes contemplam as noções de efeito-leitor e silêncio, bem como as análises de seu funcionamento no decreto de carnaval.

\section{O efeito-leitor em jogo no decreto}

Uma primeira etapa analítica é a compreensão do efeito-leitor elaborado por Pêcheux (MOLETA, 2018; BENETTI, 2016). Ele diz respeito aos lugares que os sujeitos atribuem a si e aos outros e faz parte de uma antecipação (MOLETA, 2018), em que alguém se imagina no lugar do outro, e fala a partir dessa idealização, que influencia no que será dito. Por isso, para Orlandi (2008) e Benetti (2016), existem dois leitores: o real, que efetivamente se apropria do texto; e o imaginado, aquele que o autor pensa que vai ler, mas que pode não o fazer.

Hansen (2013) e Moleta (2018) representam o efeito-leitor a partir da relação entre três pontos: A (eu); B (o outro); e C (o referente). O quadro abaixo (quadro 1) ilustra as análises do artigo, pensadas dentre uma variedade de enfoques e desdobramentos possíveis.

Quadro 1 - Análises do efeito-leitor no decreto

\begin{tabular}{|l|l|l|}
\hline \multicolumn{2}{|l|}{ Elementos } & Resultado \\
\hline A (a fanpage) & A (a fanpage) & Imagem de si própria \\
\hline A (a fanpage) & B (os seguidores) & Imagem sobre os fãs \\
\hline A (a fanpage) & C (futebol clássico) & Imagem sobre futebol \\
\hline
\end{tabular}

Fonte: elaborada pelo autor.

Acerca de $A$ sobre A, a fanpage se vê como portadora de elementos hegemônicos (CONNELL, 2005). Violência/autodestruição, vida sexual ativa, heterossexualidade, independência, etc. são correspondentes a um modelo legitimado no futebol brasileiro. A ênfase na repetição desse sentido garante também uma contraidentificação com os saberes das masculinidades subordinadas. CL se vê ainda privilegiada na relação de poder da construção da identidade masculina, o que se nota pelo uso de verbos como "decretar" ou "cumpra-se". 
A imagem de $A$ sobre $B$ é igualmente a da hegemonia e a da cumplicidade. Sobre os tipos de leitores - ou seja, os seguidores, - Orlandi (2009, p. 9) elabora a distinção entre leitor real e virtual. O leitor virtual é uma imagem projetada pelo autor de um texto, é apenas imaginária, e pode ser idealizada como "cúmplice" ou "adversária" de um texto. Essa projeção dá base para o leitor real, que ao se apropriar do texto, “[...] já encontra um leitor aí constituído com o qual ele tem de se relacionar necessariamente".

O leitor virtual da CL é cúmplice. Isto é, aqueles que se identificam plenamente com os saberes que constituem a FD "futebol clássico" e com as características da própria página, evidenciadas na análise de $A$ sobre $A$ e que são legitimadas pelo grupo. Os leitores virtuais da página são necessariamente homens identificados com os comportamentos das masculinidades hegemônicas/cúmplices. Muito embora masculinidade não seja sinônimo de "homens", (CONNELL, 2005; CONNELL, MESSERSCHMIDT, 2013), na página essa relação parece ser verdadeira.

A caracterização do leitor desejável como homem se dá pela relação com os "adversários" do decreto, leitores contraidentificados aos saberes partilhados pelo grupo e que não são idealizados como leitores reais ${ }^{12}$. A mulher, por exemplo, é negligenciada no discurso e quando muito aparece como objeto sexual com o qual os leitores possam se divertir durante o carnaval. Homens identificados com masculinidades subordinadas também são excluídos do decreto, em uma tentativa de controle dos sentidos que podem/ devem circular.

Hoff (2012) entende a diferença como instabilidade e tensão no discurso. No decreto, o conflito se traduz como a relação assimétrica entre homens e mulheres, e entre os próprios modelos de masculinidades; ilustrado pela exclusão do outro (a mulher/o subordinado) do grupo autorizado a compartilhar da identidade do grupo, na tentativa de promover a invisibilidade.

A análise de $A$ sobre C dá pistas sobre a definição do "futebol clássico brasileiro" /" verdadeiro futebol" do qual se ocupa a página, e consequentemente de alguns saberes constituintes da FD "futebol clássico": futebol praticado por e para homens heterossexuais. Mostra-se então certa indefinição sobre o que significa esse "novo futebol", oposto ao "futebol clássico". A literatura sobre movimentos de resistência (LOPES, 2015; SIMÕES, 2016a, 2016b, 2017) dá conta de um entendimento sobre futebol moderno ("futebol neoliberal"); aqui há outro entendimento ("futebol de homens hegemônicos"). Em Cenas,

12 Falar que determinados grupos não são idealizados como leitores reais não significa dizer que não existe possibilidade de eles serem público da página. Ou seja, muito provavelmente mulheres e "homens subordinados" são seguidores da página e se engajam com o decreto. 
o reforço a essa ideia se dá pela associação de jogadores de futebol aos comportamentos do decreto (SDs 1-2).

\section{SD 1 puxar "DIDICO QUERIDO O POVO ESTÁ CONTIGO" \\ SD 2 terra de Renato Gaúcho, Aloísio Chulapa e Ronaldinho}

Para compreender em profundidade essas concepções de futebol masculinizado, é feita a análise sobre os sentidos dos silêncios no decreto de carnaval (ORLANDI, 2007).

\section{O silenciamento dos subalternos no decreto}

Orlandi (2007) confere um aspecto "positivo" ao silêncio, diferente da carga negativa que lhe é atribuída costumeiramente. Sua proposição, ancorada na AD, propõe duas formas complementares: o silêncio fundante e a política do silêncio.

O silêncio fundante é a noção de que o silêncio faz parte de todo processo de significação. Ele significa por si só; não é o vazio ou mera ausência de palavras. "Quando atentamos para o silêncio, tematizando razões 'constitutivas', fazemos o percurso da relação silêncio/linguagem e estamos no domínio do silêncio fundante [...]" (ORLANDI, 2007, p. 54). Produzir sentido com palavras não é o mesmo que produzir sentido com silêncios, por mais que o dizer e o não dizer sejam correlatos.

A política do silêncio é o "silenciar", o "pôr em silêncio", dividida em dois conceitos. O primeiro é o silêncio constitutivo, em que "[...] se apagam os sentidos que se quer evitar, sentidos que poderiam instalar o trabalho significativo de uma 'outra formação discursiva', uma 'outra região de sentidos'" (ORLANDI, 2007, p. 73-74). O segundo é o silêncio local, a proibição da existência de certos sentidos - a censura propriamente dita. A política do silêncio afeta diretamente a ordem natural dos sentidos e da identidade dos sujeitos, naturalmente dispersa segundo a AD (ORLANDI, 1997, 2007; HANSEN, 2013).

Este artigo se ocupa especificamente dessa dimensão política ${ }^{13}$, onde se situa o "colocar em silêncio"; o ocultar ou proibir sentidos. É uma lógica semelhante à da identidade descrita por Silva (2014). O processo de funcionamento da língua faz com que ao dizer algo, outra coisa seja apagada; e a repetição desse sentido o solidifica. Uma das

${ }_{13}$ O silêncio fundante também é descrito, pois segundo Orlandi (2007), apesar de serem dimensões diferentes, elas estão sempre relacionadas, mesmo quando as análises enfocam uma ou outra. 
propostas de análise desenvolvida por Orlandi (2007) é justamente pela paráfrase, que permite atribuir certa regularidade ao silêncio, destacando sua materialidade histórica.

A paráfrase em questão no decreto é a da omissão dos sentidos de masculinidades subordinadas. Ao repetir durante anos os valores de violência, de vida sexual ativa e de independência, são negadas tantas outras FDs e tomadas de posição. As SDs 3-6 ilustram a fixação dos sentidos em torno de atributos de masculinidade hegemônica.

SD 3 pegar sem olhar a cara

SD 4 puxar DIDICO O POVO ESTÁ CONTIGO” nos blocos Brasilzão afora

SD 5 se perder dos amigos às $10 \mathrm{~h} 47$ e reaparecer as $17 \mathrm{~h} 23$ bêbado e com outra camisa

SD 6 ser encontrado pelos amigos deitado em posição fetal num beco escuro e falando sozinho

Na SD 3, um sentido possivelmente silenciado é o da não objetificação da mulher. "Pegar sem olhar a cara" sugere envolvimento sexual meramente para validação da masculinidade, dada a importância da vida sexual ativa para a definição do "homem macho". O "outro", que vai simplesmente "ser pego", é puramente objeto para satisfação das necessidades sexuais do "sujeito Cenas", já que pouco importa quem está do outro lado. Dada a organização da FD "futebol clássico" e sua ligação a saberes das masculinidades hegemônicas/cúmplices, esse "outro" pode ser entendido como uma mulher, de modo que o "pegar sem olhar a cara" sugere também a validação da relação de poder desigual entre o masculino e o feminino.

A SD 4 transfere os atributos dos tipos socialmente legitimados de masculinidades aos jogadores de futebol, por meio do personagem "Didico" - o ex-atacante Adriano Imperador. "O povo está contigo" porque ele representa aquilo que é valorado na Formação Discursiva "futebol clássico": é heterossexual, tem uma vida extracampo tumultuada, bebe cerveja, e frequenta a Vila Cruzeiro, favela em que foi criado, mesmo depois de ter elevado seu padrão financeiro (JORNAL EXTRA, 2017).

O sentido apagado aqui é o da possibilidade de portadores de outros tipos de masculinidade também serem dignos de terem os nomes cantados nas ruas. Por exemplo, dados os saberes que estruturam a FD "futebol clássico", parece difícil imaginar a frase "Richarlyson, o povo está contigo". Richarlyson não ostenta os atributos de masculinidade presentes no decreto. Quando foi contratado pelo Guarani (SP), o atleta foi hostilizado 
por torcedores da própria equipe pela mera possibilidade de ele ser homossexual (PIRES, 2017). "Thiago Silva, o povo está contigo" também não é possível. Não há nenhuma especulação sobre a orientação sexual do zagueiro, mas ele é tido por "fraco" por ter chorado em jogos da Seleção Brasileira ${ }^{14}$.

Os sentidos das SDs 5-6 remontam para a competitividade e para o consumo de álcool, relacionados à dominação masculina que ocorre em campos como o esporte. Ficar bêbado compõe o currículo de masculinidade proposto por Bandeira (2009, p. 69). A bebida alcoólica é entendida por ele como "ingrediente significativo nas relações entre homens" e como "catalisador" para as agressividades observadas em estádios de futebol. Os trechos selecionados do decreto dão conta de uma violência contra o próprio corpo: o exagero no álcool é tamanho ao ponto de colocar o próprio sujeito em situação de vulnerabilidade.

É aí que entra em jogo a competitividade: sendo o consumo de álcool marcador de masculinidade, não se trata simplesmente de beber, mas de ser o mais bêbado. A disputa por ser o mais ousado, o que se submete a maiores riscos, é ilustrativa de uma das instâncias da violência descritas por Connell (2005): a agressão contra homens como forma de afirmação da própria masculinidade.

Para Connell (2005), sentidos similares aos das SDs 5 e 6 evidenciam relações de dominação: hierarquização entre homens e exclusão ou dominação das mulheres, baseadas em aspectos corporais de gênero. Esse modelo de organização das práticas sociais obstrui as possibilidades de sentidos do comportamento regrado e dos usos menos bélicos do corpo. Messner (2007) argumenta que esse silenciamento ocorre em diversas instâncias dos esportes em que a combatividade é recompensada. Nas palavras do autor, os corpos por vezes são convertidos em armas nas modalidades de contato, o que ocorre também no decreto - não pelo enfrentamento físico com os outros, mas pela irresponsabilidade como forma de valentia.

O silêncio constitutivo retira da FD "futebol clássico" tudo aquilo que não é da ordem do hegemônico ou cúmplice, pela tentativa de apagamento dos sentidos contrários. Tendo em conta que "futebol clássico" é o "verdadeiro futebol”, confirma-se para a CL que existe validade apenas nesse tipo de futebol, caracterizado no decreto como aquele praticado pelos homens privilegiados pelo patriarcado (CONNELL, 2005).

14 Soares et al. (2016) investigam especificamente a representação midiática sobre as atuações do jogador na Copa do Mundo de 2014, destacando os aspectos simbólicos do ato de chorar na construção do personagem, na época capitão da Seleção Brasileira de Futebol. 
Tem-se, enfim, uma explanação da constituição identitária de Cenas Lamentáveis e uma amarração da relação masculinidade-futebol, feita pela diferença. Por meio do silêncio, percebe-se uma organização do "nós", homens hegemônicos/cúmplices, arautos de um futebol legítimo, um futebol "clássico e verdadeiro"; e "eles", mulheres e homens subordinados, que jogam um futebol "moderno", sem legitimidade e inferior, que deve ficar longe do "nosso" espaço.

Tal espaço é interditado pela marcação de diferença; acessível apenas para portadores de masculinidades hegemônicas/cúmplices. Quem não se identifica com essa FD, não pode estar presente e não é considerado leitor do decreto. É um "adversário" em nível discursivo, por se identificar com outros saberes (ORLANDI, 2008), como por praticar "outro futebol", de nível inferior, que não pode existir no "nosso" território, destinado às condutas desejadas na prática esportiva.

Para que isto ocorra, é acionado um complexo funcionamento discursivo e performático. Como indica Silva (2014), o sentido da palavra se cristaliza por sua repetição. Se confere institucionalidade e ilusão de realidade ao discurso (ORLANDI, 2005 , 2007). No decreto, se materializa a ilusão de que o futebol é, mesmo, uma prática que pode/deve ser protagonizada unicamente por determinados tipos de homens.

\section{Considerações finais}

Por meio de análises sobre o imaginário de Cenas Lamentáveis e dos sentidos do silêncio de seus decretos, chegou-se a uma compreensão do que é "verdadeiro futebol". O processo discursivo do decreto apenas pode ser explicado por meio de uma série de observações de contextos externos, como a história de movimentos torcedores, do esporte como pedagogia de gênero, e dos modelos de masculinidade das sociedades ocidentais.

Resumindo os achados de forma breve, o decreto funciona assim: ele é possivelmente pensado por e para homens identificados com modelos de masculinidades hegemônicas/cúmplices. Valores desses modelos, como a violência/autodestruição, a heterossexualidade e a independência são repetidos e vinculados a um "futebol clássico" ao mesmo tempo que silenciam masculinidades subordinadas, o que, por fim, solidifica a ideia de que "futebol clássico" é aquele que cumpre o decreto, algo que os modelos subordinados e marginalizados não podem fazer.

Além da repetição de sentidos como influenciadora dessa identidade de grupo, há também produção de identidade e diferença em curso nos decretos em todos os momentos 
detalhados acima. No entanto, nem todas as diferenças são marcadas com tanta ênfase. Em Cenas ocorre também um processo semelhante ao descrito por Woodward (2014) na formação de identidades nacionais, ou por Hoff (2012) na representação da diferença na publicidade, embora esses obviamente não sejam o caso aqui. As autoras descrevem o apagamento de certas diferenças em prol de uma homogeneidade que permita uma sensação de união.

A fanpage se organiza em torno de um futebol praticado nos anos 1990, a despeito de diferenças entre integrantes que possam se postar como um desafio a essa unicidade. Possivelmente muitos seguidores sequer tinham idade para se lembrar do futebol que era jogado naquela época; outros podem considerar essa década pior do que as anteriores; há ainda aqueles que podem se identificar com a masculinidade hegemônica e não gostarem dos anos 1990. São possíveis encaminhamentos para futuros estudos e que fogem ao que é possível no momento.

A dissertação em desenvolvimento pretende aprofundar algo mencionado apenas marginalmente durante a análise das formações imaginárias: a existência de pelo menos duas concepções sobre "futebol clássico". Uma delas é identificada na fanpage, o "futebol de macho"; outra está na bibliografia sobre o assunto, em que gênero não é categoria constituinte. Se trata de duas FDs diferentes? São posições diferentes dentro de uma mesma FD? São respostas também impossíveis por agora.

Fechando o artigo, deve-se destacar de forma explícita que o objetivo não é tachar a página, seus seguidores ou administradores como "machistas" ou "opressores", já que tal juízo de valor seria incompatível com a ética científica, além de bastante simplista e mesmo injusto. Seus discursos têm raízes em cadeias de sentidos muito anteriores, das quais os sujeitos "esquecem" para eles próprios poderem produzir sentidos. Observando essa inconsciência de um lugar relativizado, mas sem a pretensão de considerar-se dono absoluto do próprio dizer, a finalidade é simplesmente estimular o pensamento crítico sobre os dizeres e os não dizeres postos em circulação na fanpage.

\section{Referências}

AIRES, Aliana Barbosa; HOFF, Tânia. Inter-relações entre os estudos de comunicação/consumo e da análise de discurso francesa: uma perspectiva para investigar publicidade. In: CONGRESSO BRASILEIRO DE CIÊNCIAS DA COMUNICAÇÃO, 39., 2016. LocalSão Paulo. Anais [...]. LocalSão Paulo, 2016. Disponível em: http://portalintercom.org.br/anais/nacional2016/resumos/R112296-1.pdf. Acesso em: 10 fev. 2019. 
BACCEGA, Maria Aparecida. O consumo no campo comunicação/educação: importância para a cidadania. In: Estéticas midiáticas e narrativas do consumo. Rose de Melo Rocha e Vander Casaqui (org.). Porto Alegre: Sulina, 2012.

BANDEIRA, Gustavo Andrada. Eu canto, bebo e brigo... alegria do meu coração": currículo de masculinidades nos estádios de futebol. 2009. 128 p. Dissertação (Mestrado em Educação), Programa de Pós-Graduação em Educação, Universidade Federal do Rio Grande do Sul.

BENETTI, Marcia. Análise de Discurso como Método de Pesquisa em Comunicação. In: MOURA, Cláudia Peixoto de; LOPES, Maria Immacolata Vassallo de (orgs.). Pesquisa em comunicação: metodologias e práticas acadêmicas. Porto Alegre: EDIPUCRS, 2016. p.235-256.

CENAS LAMENTÁVEIS. Descubra. 2016. Disponível em: http://cenaslamentaveis.com.br/ sobre/. Acesso em: 25 nov. 2018.

CONNELL, Robert William. Masculinities. Cambridge: Polity, 2005. 2. ed.

CONNELL, Raewyn.; MESSERSCHMIDT, James W.; (trad. FERNANDES, Felipe Bruno Martins). Masculinidade hegemônica: repensando o conceito. Revista Estudos feministas, vol. 21, n. 1, p. 241-282, 2013.

FERREIRA, Maria Cristina Leandro. Linguagem, ideologia e psicanálise. Estudos da Língua (gem), n. 1, p. 69-75, 2005.

GARCÍA-CANCLINI, Néstor. Consumidores e cidadãos: conflitos multiculturais da globalização. Rio de Janeiro: Editora UFRJ, 2015.

HANSEN, Fabio. (In)verdades sobre os profissionais de criação: poder, desejo, imaginação e autoria. Porto Alegre: Entremeios, 2013.

HOFF, Tânia. Produção de sentido e publicização do discurso da diferença na esfera do consumo. In:ROCHA, Rose de Melo; CASAQUI, Vander (org.). Estéticas midiáticas e narrativas do consumo. Porto Alegre: Sulina, 2012. p. 145-161.

JORNAL EXTRA. Adriano Imperador aparece 'soltinho' em vídeo na Vila Cruzeiro. Disponível em: https://extra.globo.com/famosos/retratos-da-bola/adriano-imperador-aparece-soltinhoem-video-na-vila-cruzeiro-21630812.html. Acesso em: 25 jan. 2020. 
KENNEDY, Peter; KENNEDY, David. Football supporters and the commercialisation of football: Comparative responses across Europe. Soccer \& Society, v. 13, n. 3, p. 327-340, 2012.

LOPES, Felipe Tavares Paes. Reflexões Preliminares Sobre o "Futebol Moderno": Dominação e Resistência. In: CONGRESSO BRASILEIRO DE CIÊNCIAS DA COMUNICAÇÃO, 38., 2015. Local. Anais [...]. Local, 2015. Disponível em: http://portalintercom.org.br/anais/nacional2015/ resumos/R10-0711-1.pdf. Acesso em: 17 jul. 2018.

MESSNER, Michael. Out of Play: Critical Essays on Gender and Sport. Albany: State University of New York Press, 2007.

MOLETA, Cintia. Quando Dogville mostra os dentes: o efeito-leitor e as desordens morais no discurso fílmico de Lars Von Trier. 2018. 204 p. Dissertação (Mestrado em Comunicação), Setor de Artes, Comunicação e Design, Universidade Federal do Paraná.

ORLANDI, Eni Pulcinelli. Análise de Discurso: princípios e procedimentos. 5. ed. Campinas: Pontes, 2005.

ORLANDI, Eni Pulcinelli. As formas do silêncio: no movimento dos sentidos. 6. ed. Campinas: Editora da Unicamp, 2007.

ORLANDI, Eni Pulcinelli. Discurso e leitura. 8. ed. São Paulo: Cortez, 2008.

PIRES, Breiller. Richarlyson, de novo alvo do tormento dos ataques homofóbicos. El País, 2017. Disponível em: https://brasil.elpais.com/brasil/2017/05/09/deportes/1494343530_901105.html. Acesso em: 25 jan. 2020.

ROCHA, Rose de Melo. A pureza impossível: consumindo imagens, imaginando o consumo. Estéticas midiáticas e narrativas do consumo, v. 1, p. 21-48, 2012.

SANTOS, Irlan Simões. O público dos estádios: marcos históricos da atual elitização e arenização do futebol brasileiro. In: CONGRESSO DE CIÊNCIAS DA COMUNICAÇÃO NA REGIÃO NORDESTE. JOÃO PESSOA, 16., 2014. João Pessoa. Anais [...]., 2014, Disponível em: http://www.portalintercom.org.br/anais/nordeste2014/resumos/R42-0817-1.pdf. Acesso em: 08 jun. 2018 . 
SANTOS, Irlan Simões. Mercantilização do futebol e movimentos de resistência dos torcedores: histórico, abordagens e experiências brasileiras. Esporte e Sociedade [on-line], v. 27, n. 11, p. 1-18, 2016a. Disponível em: http://www.uff.br/esportesociedade/pdf/es2704.pdf. Acesso em: 14 jun. 2018.

SANTOS, Irlan Simões. Ódio eterno ao futebol moderno?. 2016b. Disponível em: https:// outraspalavras.net/posts/odio-eterno-ao-futebol-moderno/. Acesso em: 17 dez. 2018.

SANTOS, Irlan Simões. Novas culturas torcedoras: das arenas do futebol-negócio à resistência nas arquibancadas e redes. 2017. 245 p. Dissertação (Mestrado em Comunicação) - Faculdade de Comunicação Social, Universidade do Estado do Rio de Janeiro.

SOARES, João Paulo Fernandes et al. "O choro do capitão": notas sobre performatividades de gênero e masculinidades no futebol profissional. Movimento, v. 22, n. 4, 2016.

SILVA, Tomaz Tadeu da. A produção social da identidade e da diferença. In: SILVA, Tomaz Tadeu da (org.). Identidade e Diferença: a perspectiva dos estudos culturais. 15. ed. Petrópolis: Vozes, 2014.

WILLIAMS, John. 'Protect me from what I want': Football fandom, celebrity cultures and 'new'football in England. Soccer \& Society, v. 7, n. 1, p. 96-114, 2006.

WOODWARD, Kathryn. Identidade e Diferença: uma introdução teórica e conceitual. In: SILVA, Tomaz Tadeu da (org.). Identidade e Diferença: a perspectiva dos estudos culturais. 15. ed. Petrópolis: Vozes, 2014.

1 Mestrando no Programa de Pós-Graduação em Comunicação da Universidade Federal do Paraná, na linha de pesquisa de Comunicação e Formações Socioculturais. E-mail: elyson.gums@ gmail.com

2 Docente no Programa de Pós-Graduação em Comunicação da Universidade Federal do Paraná (UFPR) na linha de pesquisa Comunicação e Formações Socioculturais. Pesquisador nos Grupos de Pesquisa certificados no CNPq: Ensino Superior de Publicidade e Propaganda, e Estudos sobre Comunicação, Consumo e Sociedade. E-mail: fabiohansen@yahoo.com 